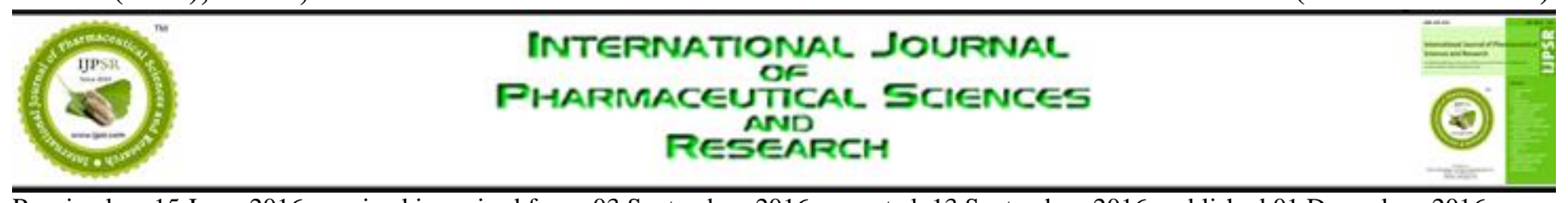

Received on 15 June, 2016; received in revised form, 03 September, 2016; accepted, 13 September, 2016; published 01 December, 2016

\title{
EFFICACY OF GARLIC IN CONJUNCTION WITH PENTOXIFYLLINE IN THE MANAGEMENT OF ORAL SUBMUCOUS FIBROSIS - A PRELIMINARY STUDY
}

\author{
Nimesh Jain * ${ }^{*}$ Rajeshwari G. Annigeri and Pratik R. Pipalia \\ Oral Medicine and Radiology, College of Dental Sciences, Davangere, Karnataka, India.
}

Keywords:

Oral submucous fibrosis, Pentoxifylline, Turmeric, Garlic, Vitamin E, Superoxide dismutase

\section{Correspondence to Author:}

Dr. Nimesh Jain

MDS, Oral Medicine and Radiology College of Dental Sciences,

Davangere, Karnataka, India.

Email: nimesh.jain02@gmail.com

\begin{abstract}
Introduction and Objectives: Oral submucous fibrosis (OSMF) is a chronic, progressive, and irreversible disease of the oral mucosa. Though numerous modalities have been tried but all are palliative and have no curative value. Pentoxifylline possessing vasorelaxive and antifibrotic properties believed to potentiate the anti-inflammatory, anti-oxidant and immune modulating properties of garlic. So, the present preliminary clinical trial was undertaken to evaluate the efficacy of Garlic in conjunction with pentoxifylline in the management of OSMF. Methods: The study consisted of 15 OSMF patients. Pentoxifylline (400 mg) was administered thrice daily along with garlic pearls, 2 pearls; thrice daily. Drugs were administered systemically after food for a duration of 3 months. Patients were evaluated every 15 days for the assessment of clinical parameters, i.e. burning sensation, reduction in mouth opening, tongue protrusion and cheek flexibility. Pre and post treatment SOD level were measured and compared. The improvement was assessed at the end of the study. Results: All the patients were males with the mean age of 26.04 years. Patients exhibited a mean reduction of $95.68 \%$ in burning sensation and an increment of $5.37 \mathrm{~mm}$ in mouth opening. The cheek flexibility and tongue protrusion also showed significant improvements in the study groups. All the patients showed significant $(\mathrm{p}>0.001)$ improvement in SOD levels following treatment. Conclusion: Overall assessment of the all clinico-biochemical parameters showed a significant improvement. Thus, choice of such therapy is beneficial, affordable, easily available and most importantly a non-invasive treatment modality for OSMF.
\end{abstract}

INTRODUCTION: Most conditions affecting the oral mucosal health are acquired through environment and lifestyle factors. The use of tobacco and tobacco products has unfortunately pervaded the ordinary household from being only occasional fashionable attributes to chronic potential toxicants compromising the health of the consumers immensely. Initially, it starts with occasional usage and with time, these products make way into one's lifestyle resulting in addiction.

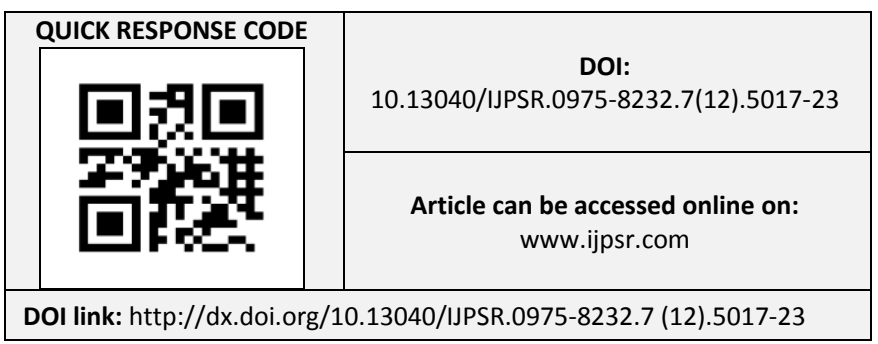

By the time one realizes the consequences of this addiction, it's too late to revert back to normalcy since the damage is already done.

Management of Oral submucous fibrosis (OSMF) has been a real challenge faced by the oral physicians. It is a chronic, insidious disease that is associated with significant functional morbidity and an increased risk of malignancy. ${ }^{1}$

Though the etiology is elusive, numerous studies have explained its association with the usage of areca nut and betel quid (BQ) which are the practices of great antiquity in India and South East Asia. The chewing of $\mathrm{BQ}$ is associated with increased lipid peroxidation thereby generating free radicals and producing oxidative stress. Various experimental studies have shown that increased 
oxidative stress with decreased superoxide dismutase (SOD) level can play a key role in the pathogenesis of OSMF. ${ }^{2,3}$

As the etiology of the disease is not singlet, many treatment modalities have been tried and validated in the literature. ${ }^{4}$ Steroids, antioxidants, enzymes like collagenase 5, chymotrypsin 6, and hyaluronidase ${ }^{6,7}$, placental extracts ${ }^{8}$, Interferon- $\gamma$ 9 , lycopene ${ }^{10}$, peripheral vasodilators 11, 12 levamisole ${ }^{13}$, immune milk ${ }^{14}$, physiotherapy ${ }^{15}, 16$ and surgical modalities $17,18,19$ have been cited in the literature, yet they have been palliative and proven to be of minimal benefit. Although intralesional steroids have shown improvement, but are associated with significant discomfort, pain and infection at the injection site and reduction in mouth opening over a period of follow-up as rebound fibrosis is often precipitated as mechanical and chemical injuries in the oral mucosa heal by fibrosis. ${ }^{13}$

Pentoxifylline is a tri-substituted methyl xanthine derivative, with several biological actions. It has been tried in various clinical trials and proved beneficial in the management of OSMF. $20,21,22$ Various hypotheses have been put forward regarding the mechanism of action of pentoxifylline and its cellular and molecular effects, based on human and animal studies. This includes hemorheological, anti-fibrinolytic, immune modulation, anti-tumour necrosis factor (TNF) effects along with its effects on endothelial cells and adhesion molecules. ${ }^{20}$ Since OSMF is anteceded by various inflammatory and immunological factors which progressively lead to fibrosis of sub mucosa, so the property of pentoxifylline that may be far-reaching in the management of OSMF, is perhaps its effect on the fibroblast and its role in fibrinolysis, immunomodulation and inhibition of TNF- $\alpha$.

There are hundreds of herbs used throughout the world that are beneficial in various disorders. By using herbs in their complete form, the body's healing process utilizes a balance of ingredients provided by nature. One such therapeutic modality is garlic, possessing immunomodulatory, antioxidant, chemopreventive, anti-inflammatory and vasorelaxive properties. 23,24 All these properties of garlic make it a promising approach in the treatment of OSMF.

So, the aim of the current study is 1) to compare and evaluate the efficacy of Pentoxifylline with Garlic in the management of OSMF 2) to compare and evaluate oxidative stress by measuring serum superoxide dismutase levels before and after the treatment.

To the best of our knowledge, this is the first clinical trial that compares the Super Oxide Dismutase (SOD) levels before and after treatment. Till date, there are no published reports of the use of this combination of drugs, i.e. Pentoxifylline and Garlicin the management of OSMF in patients.

\section{MATERIALS AND METHODS:}

Study setting: The present clinical study was conducted in the Department of Oral Medicine and Radiology, College of Dental Sciences, Davangere. The study was carried out for a duration of 10 months from February 2014 till November 2014. The study protocol was approved by the Institution Review Board of the same (CODS/IRB/08/20132014) Study was done in compliance with the declaration of Helsinki.

Study subjects: A total of 15 clinically diagnosed OSMF patients of either sex were included who were willing to quit gutka/arecanut chewing habit and who have not undergone any treatment for OSMF in the past 3 months, whereas any patients with coexisting systemic illness and who have taken treatment in any form were excluded. Written informed consent was obtained from each patient at the outset of the study and all the patients was explained about the need and design of the study. Before commencing the treatment, patients were counseled regarding habit cessation of areca nut, gutka, pan masala chewing.

Study Parameters: A detailed proforma was used to record the patients' data. Clinical parameters, i.e. burning sensation, mouth opening, tongue protrusion and cheek flexibility served as a guideline to measure the improvement in signs and symptoms. The Visual Analogue Scale (VAS) of 110 was used to measure the intensity of burning sensation. 
Mouth opening was measured in $\mathrm{mm}$, using Vernier caliper from the mesioincisal angle of upper central incisor to lower central incisor. Based on the mouth opening, clinically the patients were categorized into five groups,

- Stage I: $>40 \mathrm{~mm}$

- Stage II: $31-40 \mathrm{~mm}$

- Stage III: $21-30 \mathrm{~mm}$

- Stage IV: $11-20 \mathrm{~mm}$

- Stage $\mathrm{V}:<10 \mathrm{~mm}$

Cheek flexibility was measured using Mathur and Jha method ${ }^{25}$ and Tongue protrusion was recorded using Vernier caliper from the mesioincisal angle of upper central incisor to the tip of the tongue when the mouth is wide open and tongue is at its maximum extension. It was measured in millimeters $(\mathrm{mm})$. Clinical parameters measurement procedure was repeated thrice at every visit and the average was taken into consideration. The clinical parameters recorded at the first visit were considered as base line. Each patient was then subjected to the study drug i.e. Pentoxifylline along with Garlic pearls. Pentoxifylline was administered systemically, thrice daily as tablets (Trental - 400mg, Sanofi India Ltd.), after food for three continuous months. These patients were also given Garlic pearl (Ranbaxy) containing garlic oil $0.25 \%$ w/w, systemically two pearls twice daily after food for three months. Further evaluation and recording of clinical parameters were carried out for all the patients at each of the six recall visits. A total of 7 values were hence obtained for each clinical parameter. At each appointment, patients were asked about any discomfort they felt subsequent to the drug administration after their enrolment into this study.

Biochemical parameter: Serum SOD was estimated using Marklund and Marklund method. ${ }^{26}$
Pre and post treatment SOD levels were measured and compared.

Statistical analysis: Descriptive data that included mean and percentages were calculated for each group and were used for analysis. Paired t- test was used for intragroup comparison, and repeated measures ANOVA were used to compare the values within the group at different intervals. For all the tests, a p-value of 0.05 or less was considered for statistical significance and SPSS 20.0 software was used for analysis.

RESULTS: The study consisted a total of 15 clinically diagnosed OSMF patients. All patients were males with a mean age of $24.46 \pm 4.97$ years (Range 18 - 38 years). All the patients had the habit of chewing gutka or areca nut in one or the other form.

In the present study, patients reported primarily with the chief complaint of burning sensation encountered with hot and spicy food and reduced mouth opening whereas it was an adventitious finding in few patients. Blanching of the buccal mucosa was ubiquitous in all the patients accompanied by palpable fibrous bands over buccal mucosa on intraoral examination. All the patients were divided into various clinical stages based on mouth opening (Table 1).

TABLE 1: DISTRIBUTION OF PATIENTS IN VARIOUS CLINICAL STAGES

\begin{tabular}{cc} 
Clinical Staging & No. of patients Pre-treatment \\
Stage I & - \\
Stage II & $2(13.3 \%)$ \\
Stage III & $12(80 \%)$ \\
Stage IV & $1(6.66 \%)$ \\
Total & $\mathbf{1 5}$ \\
\hline
\end{tabular}

Clinical parameters pre and post treatment have depicted in Table 2.

TABLE 2: INTRA GROUP COMPARISON BEFORE AND AFTER THE TREATMENT

\begin{tabular}{cccc}
\hline Drug & \multicolumn{2}{c}{ Pentoxifylline + Garlic } & \\
\cline { 2 - 4 } Patients & Pre & Post & p - value \\
\hline Burning sensation (VAS) & $6.26 \pm 2.98$ Range $2-10$ & $0.27 \pm 0.79$ & $0.001^{*}$ \\
Mouth opening (mm) & $26.33 \pm$ 3.94 Range: $19-34$ & $31.70 \pm 3.79$ & $<0.001^{*}$ \\
Tongue protrusion (mm) & $38 \pm 8.95$ Range: $25-55$ & $42.43 \pm 8.82$ & $<0.001^{*}$ \\
Cheek flexibility (mm) & $2.6 \pm 1.18$ Range: $1-5$ & $4.33 \pm 1.17$ & $<0.001^{*}$ \\
\hline
\end{tabular}


Out of 15 patients in this group, no patient was there in stage I, 2 patients resided in stage II, 12 patients in stage III and 1 patient belonged to stage IV. The patients in stage II perceived reduction in burning sensation by $100 \%$ along with an increment of $4.5 \mathrm{~mm}$ in mouth opening, $3 \mathrm{~mm}$ in tongue protrusion and $0.5 \mathrm{~mm}$ improvement in cheek flexibility. In stage III, 10 out of 12 patients exhibited a complete reduction in burning sensation, a mean gain of $5.29 \mathrm{~mm}$ in mouth opening, an advancement of $4.87 \mathrm{~mm}$ in tongue protrusion and $1.91 \mathrm{~mm}$ increase in cheek flexibility. The patient of stage IV showed $100 \%$ reduction in burning sensation along with $8 \mathrm{~mm}$ augmentation in mouth opening, $3 \mathrm{~mm}$ improvement in tongue protrusion and $2 \mathrm{~mm}$ increase in cheek flexibility.

On biochemical investigation, the mean serum level of SOD following treatment was statistically escalated when compared to the baseline values (Table 3).

TABLE 3: CORRELATION OF CLINICAL STAGING WITH SUPEROXIDE DISMUTASE LEVEL ALONG WITH PRE AND POST TREATMENT CHANGES

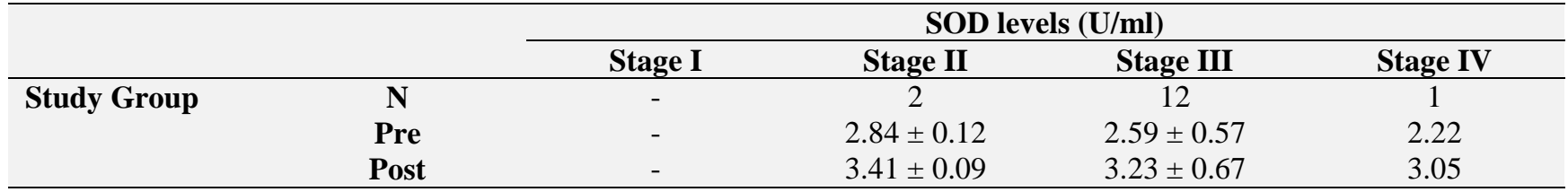

DISCUSSION: OSMF is considered as major oral health problem with the high degree of malignant potential. Oxidative stress is implicated in the pathogenesis of various diseases including oral cancer. Several experimental studies have associated reactive oxygen species induced lipid peroxidation i.e. malondialdehyde in the development of potentially malignant conditions and malignancy. Prevention against lipid peroxidation mediated damage is done by nonenzymatic antioxidants, especially beta-carotene and Vitamin $\mathrm{E}$ and enzymatic antioxidant like superoxide dismutase. OSMF being a potentially malignant condition and associated with carcinogens like tobacco, is reported to show increased lipid peroxidation product and decreased antioxidant levels like SOD. ${ }^{2,27}$

Although many factors have been elicited and worked upon, no concrete etiology/ pathophysiology has been elicited and thus, no effective treatment is available for this progressively disabling condition with high malignant potential. Despite diverse clinical trials, no single drug has bestowed complete relief of symptoms of OSMF; this precipitates the need for the use of a combination of drugs to treat the condition.

The mean age of the patients was $24.46 \pm 4.97$ years (Range 18 - 38 years) and all were male. Certain epidemiological studies have reported the common age of occurrence of OSMF as 20-29 years. This has been attributed to the dynamic changes in the trends among young individuals due to increased social encounters and economic liberty in developing nations like India. ${ }^{28}$

It was noticed that all the patients had the habit of chewing gutka or areca nut. Out of 15 patients, 13 $(86.66 \%)$ patients chewed gutka whereas 2 (13.33 $\%)$ patients were chewing pan with areca nut. This finding is in consensus with several studies where patients had habit of arecanut chewing in one or the other form. ${ }^{29,30}$

Burning Sensation encountered with hot and spicy food along with reduced mouth opening are the two most debilitating conditions which affect the quality of life and with which patient usually present to the clinic. Various studies have demonstrated that patients present with this chief complaint in most of the cases. ${ }^{31,32}$

Epithelial atrophy primarily leads to burning sensation which further curtails their dietary intake and leads to nutritional deficiencies. Patients exhibited a mean reduction of $95.68 \%$ in burning sensation. The relief was observed in most of the cases by the end of $4^{\text {th }}$ visit whereas $13(86.66 \%)$ patients achieved complete relief from burning sensation by the end of the treatment. 
Results of our study were in consonance with various studies done to reduce the burning sensation by administration of Intralesional steroids (89.28\%), Intralesional IFN $\gamma^{9}(60 \%)$, Immunized milk $^{14}(77.8 \%)$, Oxitard capsules ${ }^{34}(71.6 \%)$, Antoxid tablets (86.6\%) and Levamisole ${ }^{35}(98.6 \%)$ whereas improved relief was attained when compared to various studies done with pentoxifylline alone. ${ }^{21,} 36$ Improvement in loco regional blood flow by Pentoxifylline accounts for the significant reduction in burning sensation. It improves blood flow by a multi-tiered process. ${ }^{37}$

Restriction of mouth opening was evident in all the patients in our study which is attributed to the fibrous bands in the buccal mucosa, vestibular and retro molar region, loss of elasticity and resilience of mucosa, acuteness and severity of symptoms. In the present study, improvement in the mouth opening was highly significant statistically ( $\mathrm{p}<$ 0.001 ) in the subsequent visit. At the end of the treatment, a mean increment of $5.37 \pm 0.15 \mathrm{~mm}$ was attained from the 1st visit of the patient which was highly significant $(p<0.001)$. Enhancement in mouth opening varied from minimum being $2 \mathrm{~mm}$ in one patient to a maximum of $9 \mathrm{~mm}$ in another patient when compared at the end of the treatment from baseline.

Superior results have been obtained in the present study when compared to those achieved by disparate clinical trials with systemic or topical administration of drugs i.e. Micronutrients ${ }^{38}$ (2.9 $\mathrm{mm})$, Immune milk ${ }^{14}$ (3 mm), Levamisole ${ }^{35}$ (3.1 $\mathrm{mm})$, Antioxidants ${ }^{35}$ (3.2 mm), Lycopene 39,40 (3.4mm, $4.48 \mathrm{~mm})$, Lycopene and steroid injections ${ }^{41}$ (4.6mm), Aloe vera (topical gel) ${ }^{42,43}$ (4.8 mm, $5.1 \mathrm{~mm})$, Spirulina ${ }^{43}(9 \mathrm{~mm})$. However various clinical trials with intralesional injections have shown a substantial increment in mouth opening but discomfort to the patient, rebound fibrosis and patient compliance questions its application. ${ }^{44}$

A mean improvement of $4.43 \pm 0.13 \mathrm{~mm}$ was procured. The difference was statistically significant in all the visits $(\mathrm{p}<0.001)$. Enhancement in tongue protrusion varied from minimum being 2 $\mathrm{mm}$ in one patient to a maximum of $8 \mathrm{~mm}$ in another patient when compared at the end of the treatment from baseline. Our results were in accordance with another study published in 2004 which showed a mean improvement of $5 \mathrm{~mm}$ in 34 OSMF cases where they were subjected to treatment with antoxid tablets. ${ }^{45}$

After the completion, a net hike of $1.73 \pm 0.01 \mathrm{~mm}$ was calculated which was significant $(p<0.005) .1$ patient showed no improvement in cheek flexibility contrary to the maximum improvement of $3 \mathrm{~mm}$ in one patient from baseline to the end of follow-up in this group. A preliminary study was conducted in 2012 with topical Aloe vera gel v/s antioxidant capsules. Improvement in cheek flexibility was found to be $0.06 \mathrm{~cm}$ and $0.1 \mathrm{~cm}$ respectively. The results of our study were inferior but in accordance with the results of this study. ${ }^{42}$

Various authors observed a decrease in SOD levels in OSMF when compared to healthy controls. ${ }^{2,46} \mathrm{It}$ can be attributed to utilization of the antioxidant by affected tissues or in combating the excessive oxidative stress in circulation. This makes SOD may a potential biochemical index for evaluating the disease process.

Also, in the present study on correlating the clinical staging with SOD levels, it was contemplated that the SOD level was higher in the early stages of OSMF and decreased with the advancing stages of OSMF. Thus, it can be concluded that lipid peroxidation increases with severity of the disease reflecting the extent of tissue injury, so progression of disease leads to higher tissue damage thereby reducing the level of anti-oxidants in the body. ${ }^{47}$

There was a significant increase in SOD levels post-treatment in all the patients with the mean increase being $0.68 \pm 0.04 \mathrm{U} / \mathrm{ml}$ (Pre - $2.55 \pm 0.34$ $\mathrm{U} / \mathrm{ml}$; Post $-3.23 \pm 0.38 \mathrm{U} / \mathrm{ml})$. The increment was attributed to the fact that garlic scavenges ROS, inhibits lipid oxidation and lipid peroxide formation, it increases the levels of cellular glutathione and ROS scavenging enzymes.

One patient complained of nausea and stomach upset which can be because of pentoxifylline, and it was corrected by reducing the dosage of the drug whereas 2 patients complained of garlic odor from the mouth following the consumption of the drug. The garlic breath used to persist for few hours subsequent to the intake of the drug, but patients tolerated it well and continued the treatment further. 
The beneficial results obtained in our study is attributed to Pentoxifylline, which is denominated as a rheologic modifier because it improves microcirculation and decreases aggregation of platelet as well as granulocyte adhesion. It possesses fibrinolytic activity and contemporary work has delineated its ability to decrease the production of TNF $\alpha$ and reduce some of the systemic toxicities mediated by IL 2 . These two cytokines are important mediators of the inflammatory response. In addition, pentoxifylline has been shown to increase the production of PGE2 and PGI2 by vascular epithelium, important in maintaining cellular integrity and homeostasis after acute injury. In the light of these findings, effects of pentoxifylline in the management of OSMF can be substantiated. ${ }^{21,22}$

Also, Garlic possessing antioxidant, antiinflammatory, chemopreventive, immuno modulatory properties reckon up the effects of pentoxifylline and showed potent results. As cited in the pathogenesis of OSMF, various inflammatory cytokines cause fibrosis to occur, where garlic, a potent anti-inflammatory exerts its action and also quenches the ROS generated being a potent antioxidant. ${ }^{48}$

As no published data reports the treatment of OSMF with garlic hence our results cannot be judged in comparison with other studies, whereas present study has achieved superior results than several studies rendered with pentoxifylline alone, reinforcing the superior efficacy of garlic with pentoxifylline in the management.

Less Sample size and daily consumption of garlic which might have interfered with the results were the limitations of the study which can be overcome in future by further studies involving larger sample size and longer periods of follow-ups.

CONCLUSION: Improvement in the clinical and biochemical parameters obtained in our patients is a promising finding towards establishing the use of Pentoxifylline in conjunction with Garlic as one of the treatment modalities for the management of OSMF. Thus, choice of such therapy is beneficial, affordable, easily available and most importantly a non-invasive treatment modality to those affected with OSMF.

\section{REFERENCES:}

1. Gupta M.K, Mhaske S, Raju R, Imtiyaz. Oral submucous fibrosis - Current Concepts in Etiopathogenesis. People's J Sci Res 2008;(1):39-44.

2. Metkari S, Tupkari J, Barpande S. An estimation of serum malondialdehyde, superoxide dismutase and vitamin $\mathrm{A}$ in oral submucous fibrosis and its clinicopathologic correlation. J Oral Maxillofac Pathol 2007;11:23-7

3. Bapriya R, Kumaraguruparan R, Nagini S, Thangavelu A. Oxidantantioxidant status in oral precancer and oral cancer patients. Toxicol mech methods. 2003; 13(1):77-81.

4. Fedorowicz Z,Chan Shih-Yen E, Dorri M, Nasser M, Newton T, Shi L. Interventions for the management of oral submucous fibrosis. Cochrane Database Syst Rev. 2008; (4):1-17.

5. Lin HJ, Lin JC. Treatment of oral submucous fibrosis by collagenase: effects on oral opening and eating function. Oral Dis. 2007; 13:407-13.

6. Gupta D, Sharma SC. Oral submucous fibrosis- A new treatment regimen. J Oral Maxillofac Surg.1988; 46: 83033.

7. Borle RM, Borle SR. Management of OSMF: A conservative approach. J Oral Maxillofac Surg. 1991;49: 788-91.

8. Katharia S K, Singh S P, Kulshreshtha V K. The effects of placental extract in management of oral submucous fibrosis.Indian J Pharmacol 1992;24:181-83.

9. Haque MF, Meghji S, Nazir R, Harris M. Interferon gamma (IFN- $\square$ ) may reverse oral submucous fibrosis. J Oral Pathol Med. 2001; 30: 12-1.

10. Kumar A, Bagewadi A, Keluskar V, Singh M. Efficacy of lycopene in the management of oral submucous fibrosis. Oral Surg Oral Med Oral Pathol Oral Radiol Endod 2007; 103:207-13.

11. Sharma JK, Gupta AK, Mukhija RD, Nigam P. Clinical experience with the use of peripheral vasodilator in oral disorders. Int J Oral Maxillofac Surg.1987; 16: 695-9.

12. Rajendran R, Rani V, Shaikh S. Pentoxifylline therapy: A new adjunct in the treatment of oral submucous fibrosis. Indian J Dent Res.2006; 17:190-8.

13. Jirge V, Shashikanth MC, Ali IM, Anshumalee N. Levamisole and antioxidants in the management of OSMF: A comparative study. JIAOMR. 2008; 20(4):135-140

14. Tai YS, Liu BY, Wang JT, Sun A, Kwan HW, Chiang CP. Oral administration from cows immunized with human intestinal bacteria leads to significant improvements of symptoms and signs in patients with oral submucous fibrosis. J Oral Pathol Med. 2001; 30:618-25.

15. Cox S, Zoellner H. Physiotherapeutic treatment improves oral opening in oral submucous fibrosis. J Oral Pathol Med. 2009; 38: 220-6.

16. Gupta DS, Gupta MK, Golhar BL. Oral submucous fibrosis - a clinical study and management by physiofibrolysis (MWD). Journal Indian Dent Asso. 1980; 52: 375-8.

17. Shah A, Raj S, Rasaniya V, Patel S, Vakade M. Surgical management of oral submucous fibrosis with "Opus 5" diode laser. J Oral Laser Applications 2005; 5: 37-3.

18. Gnanam A, kannadasan K, Venkatachelapathy S, David J. Multimodal treatment options for OSMF., SRM university journal of dental sciences 2010;1(1): 26-29.

19. Mokal NJ, Raje RS, Ranade SV, Prasad JSR, Thatte RL. Release of oral submucous fibrosis and reconstruction using superficial temporal fascia flap and split skin graft- a new technique.Br J Plast Surg. 2005; 58(8):1055-60. 
20. Rajendran R, Rani V, Shaikh S. Pentoxifylline therapy: a new adjunct in the treatment of oral submucous fibrosis. Indian J Dent Res 2006; 17:190-8.

21. Mehrotra R, Singh HP, Gupta SC, Singh M, Jain S. Pentoxifylline therapy in the management of oral submucous fibrosis. Asian Pac J Cancer Prev 2011; 12:971-4.

22. Patil S, Maheshwari S. Efficacy of pentoxifylline in the management of oral submucous fibrosis. J Orofac Sci 2014; 6:94-8.

23. Tripathi K. A Review-Garlic, the Spice of Life-(Part $-\mathrm{I})$. Asian J. Research Chem. 2009; 2(1):8-13.

24. Amagase H. Clarifying the real bioactive constituents of garlic. J Nutr. 2006 Mar; 136:716-25S.

25. Mathur RM, Jha T. Normal oral flexibility-A guideline for SMF cases. J Ind Dent Assoc. 1993;64(4):139-43.

26. Marklund S, Marklund G. Involvement of the superoxide anion radical in theautoxidation of pyrogallol and a convenient assay for superoxide dismutase. Eur $\mathbf{J}$ Biochem. 1974 Sep 16; 47(3):469-74.

27. Gurudath S, Naik R, Ganapathy K, Guruprasad Y, Sujatha D, Pai A. Superoxide dismutase and glutathione peroxidase in oral submucous fibrosis, oral leukoplakia, and oral cancer: A comparative study. Asian Pac J Cancer Prev. 2012; 13(9): 4409-12.

28. Singh $\mathrm{S}$ et al. "Clinico-Pathological Evaluation and Correlation of Stages of Oral Submucous Fibrosis with Different Habits." J Interdiscipl Med Dent Sci 2015; 3.168:2.

29. Angadi PV, Rekha KP. "Oral submucous fibrosis: a clinicopathologic review of 205 cases in Indians." Oral maxillofac surg2011; 15:15-19.

30. Nigam, Nitin Kumar, et al. "Prevalence of oral submucous fibrosis among habitual gutkha and areca nut chewers in Moradabad district." J Oral Biol Craniofac Res. 2014 JanApr; 4(1): 8-13.

31. Patwardhan N, Thakar S, Prabhakar L, Motghare V, Chaudhry $\mathrm{M}$ et al. Prevalence of osmf amongst factory workers in Delhi NCR: a cross-sectional study. TMU J. Dent.2015; 2(1):9-11.

32. Gupta, Juhi, S. V. Srinivasan, and J. Daniel. "Efficacy of betamethasone, placental extract and hyaluronidase in the treatment of OSMF: A comparative study." EJ Dent 2012; 2: 132-5.

33. Singh M, Niranjan HS, Mehrotra R, Sharma D, Gupta SC. Efficacy of hydrocortisone acetate/hyaluronidase vs triamcinolone acetonide/hyaluronidase in the treatment of oral submucous fibrosis. Indian J Med Res. 2010; 131:6659.

34. Patil S, Santosh BS, Maheshwari S, Deoghare A, Chhugani S, Rajesh PR. Efficacy of oxitard capsules in the treatment of oral submucous fibrosis. J Can Res Ther 2015; 11:291-4.

35. Jirge V, Shashikanth M C, Ali I M, Anshumalee N. Levamisole and antioxidants in the management of oral submucous fibrosis: A comparative study. J Indian Acad Oral Med Radiol 2008;20:135-40
36. Aara A, Satishkumar GP,C Vani , Venkat Reddy M, Sreekanth K, Ibrahim M. Comparative Study of Intralesional Dexamethasone, Hyaluronidase \& Oral Pentoxifylline in Patients with Oral Submucous Fibrosis. Global Journal of Medical Research. 2012; 12(7): 1-14.

37. Prabhu N, Rao SS, Kottershetti SM, Baliga SD, Hallikerimath SR, Angadi PV, Issrani R. OSF patients. Pentoxifylline in patients with oral submucous fibrosis-A randomized clinical trial. J Maxillofac Oral Surg. 2015 Mar; 14(1): 81-89.

38. Thakur N, Keluskar V, Bagewadi A, Shetti A. Effectiveness of micronutrients and physiotherapy in the management of oral submucous fibrosis. Int J Contemp Dent 2011; 2:101-5.

39. Karemore TV, Motwani M. Evaluation of the effect of newer antioxidant lycopene in the treatment of oral submucous fibrosis. Indian J Dent Res 2012; 23:524-8

40. Kumar A, Bagewadi A, Keluskar V, Singh M. "Efficacy of lycopene in the management of oral submucous fibrosis." Oral Surg Oral Med Oral Pathol Oral Radiol Endod. 2007 Feb; 103(2):207-13.

41. Singh D, Shashikanth MC, Misra N, Agrawal S. Lycopene and intralesional betamethasone injections in the management of oral submucous fibrosis . J Indian Acad Oral Med Radiol 2014;26:2

42. Sudarshan, R., Annigeri, R. G. and Sree Vijayabala, G. (2012), Aloe vera in the treatment for oral submucous fibrosis - a preliminary study. J Oral Pathol Med. 2012 Nov; 41(10): 755-61.

43. Patil S, Al-Zarea BK, Maheshwari S, Sahu R. Comparative evaluation of natural antioxidants spirulina and aloe vera for the treatment of oral submucous fibrosis. J Oral Biol Craniofac Res. 2015 Jan-Apr;5(1):11-5

44. Sumanth, K. N., Dr Ongole, and Jyotsna Rimal. "Efficacy of Dexamethasone Mucosal Patch for Oral Submucous Fibrosis (OSMF)-A Pilot Study." Int Poster J Dent Oral Med 12.2 (2010): Poster-484.

45. Gupta S, Reddy MVR, Harinath BC. Role of oxidative stress and antioxidants in aetiopathogenesis and management of oral submucous fibrosis. Indian $\mathrm{J}$ Clin Biochem. 2004 Jan; 19(1): 138-141.

46. Avinash Tejasvi ML, Bangi BB, Geetha P, Anulekha Avinash CK, Chittaranjan B, Bhayya H, Donempudi P. Estimation of serum superoxide dismutase and serum malondialdehyde in oral submucous fibrosis: a clinical and biochemical study. J Cancer Res Ther. 2014 Jul-Sep; 10(3):722-5

47. Raina C, Raizada RM, Chaturvedi VN, Harinath BC, Puttewar MP, Kennedy AK. Clinical profile and serum beta-carotene levels in oral submucous fibrosis. Indian $\mathrm{J}$ Otolaryngol Head Neck Surg. 2005 Jul; 57(3):191-5.

48. Ziu MM, Giasuddin ASM, Mohammad AR. The effect of garlic oil (allium sativum) on DMBA induced salivary gland tumorigenesis in rat. Journal of Islamic Academy of Sciences. 1994; 7(3):189-192.

\section{How to cite this article:}

Jain N, Annigeri RG and Pipalia PR: Efficacy of garlic in conjunction with pentoxifylline in the management of oral submucous fibrosis a preliminary study. Int J Pharm Sci Res 2016; 7(12): 5017-23.doi: 10.13040/IJPSR.0975-8232.7(12).5017-23.

All @ 2013 are reserved by International Journal of Pharmaceutical Sciences and Research. This Journal licensed under a Creative Commons Attribution-NonCommercial-ShareAlike 3.0 Unported License.

This article can be downloaded to ANDROID OS based mobile. Scan QR Code using Code/Bar Scanner from your mobile. (Scanners are available on Google Playstore) 